Christiane S. Hartog Hanne I. Jensen

\section{Family-centered ICU care may be good for everyone}

Received: 30 May 2013

Accepted: 5 June 2013

Published online: 25 June 2013

(C) Springer-Verlag Berlin Heidelberg and ESICM 2013

\section{S. Hartog ( $)$}

Department of Anesthesiology and Intensive Care, Center for Sepsis Control and Care, Jena University Hospital, Erlanger Allee 101, 07747 Jena, Germany

e-mail: Christiane.Hartog@med.uni-jena.de

Tel.: +49-3641-9323171

Fax: +49-3641-9323102

H. I. Jensen

Department of Anaesthesiology, Vejle and Middelfart Hospitals, Vejle, Denmark

In this issue of ICM, Irene Jongerden and her colleagues [1] present the results of a before-and-after study that explores the effect of a change in ICU environment on family and patient satisfaction. Family satisfaction was measured by the FS-ICU [2-4], a much used and previously validated tool, while patient satisfaction was elicited by using an adapted version of this questionnaire. A similar approach has been taken previously by a Swiss group [5]. The structural intervention was a move of the ICU to new premises, which entailed a bundle of changes. New rooms were single-bed rooms, noise-reduced, with increased privacy, more space around each bed, natural lighting and windows with a view. There were also changes in workflow, visual display of other patients via the bedside monitor, and medication prepared in a satellite pharmacy, thereby reducing medication errors. In addition, the number of family rooms was increased, and facilities for families were improved. In association with these changes, both overall family and patient satisfaction increased significantly.
This study is important for several reasons: It is one of the first to show improvement in family satisfaction with an intervention (suggesting responsiveness to change), and it is one of the first that documents an effect of changing the ICU environment on families. Interestingly, satisfaction of families and patients increased not only in relation to the ICU environment, but to the ICU experience, specifically staff behavior toward families and patients. In the new ICU, families stated that staff provided better emotional support, acted with more courtesy, respect, and compassion, and were more willing to answer questions. Patients found that staff treated them with more courtesy, compassion, and respect, individual staff members were better recognizable, and management of pain improved (Fig. 1). These findings suggest that structural changes may have indirectly affected ICU care by improvement of team collaboration and support of family- and patient-centered behavior. Possibly working conditions were made easier for staff by providing more space around the bed and improving workflow. Reducing noise levels may also lower stress for nurses and physicians. It may also be easier for staff to provide emotional support to patients and families who are well satisfied with the environment. Alternatively, it is also possible that the improved environment influenced patient and family perceptions of these other aspects of care through a "halo effect" [6]. Nonetheless, these evaluations of diverse aspects of care improved.

Defining indicators to improve quality of care for critically ill patients is an important issue [7]. Increasingly, family satisfaction with care is becoming an accepted measure of quality of care [8], and measurement of family or patient satisfaction in the ICU is already recognized as a quality indicator in several countries, including the Netherlands [9]. The study by Jongerden et al. provides further data to support that family- and patient-reported outcomes should be included when measuring quality in intensive care. 

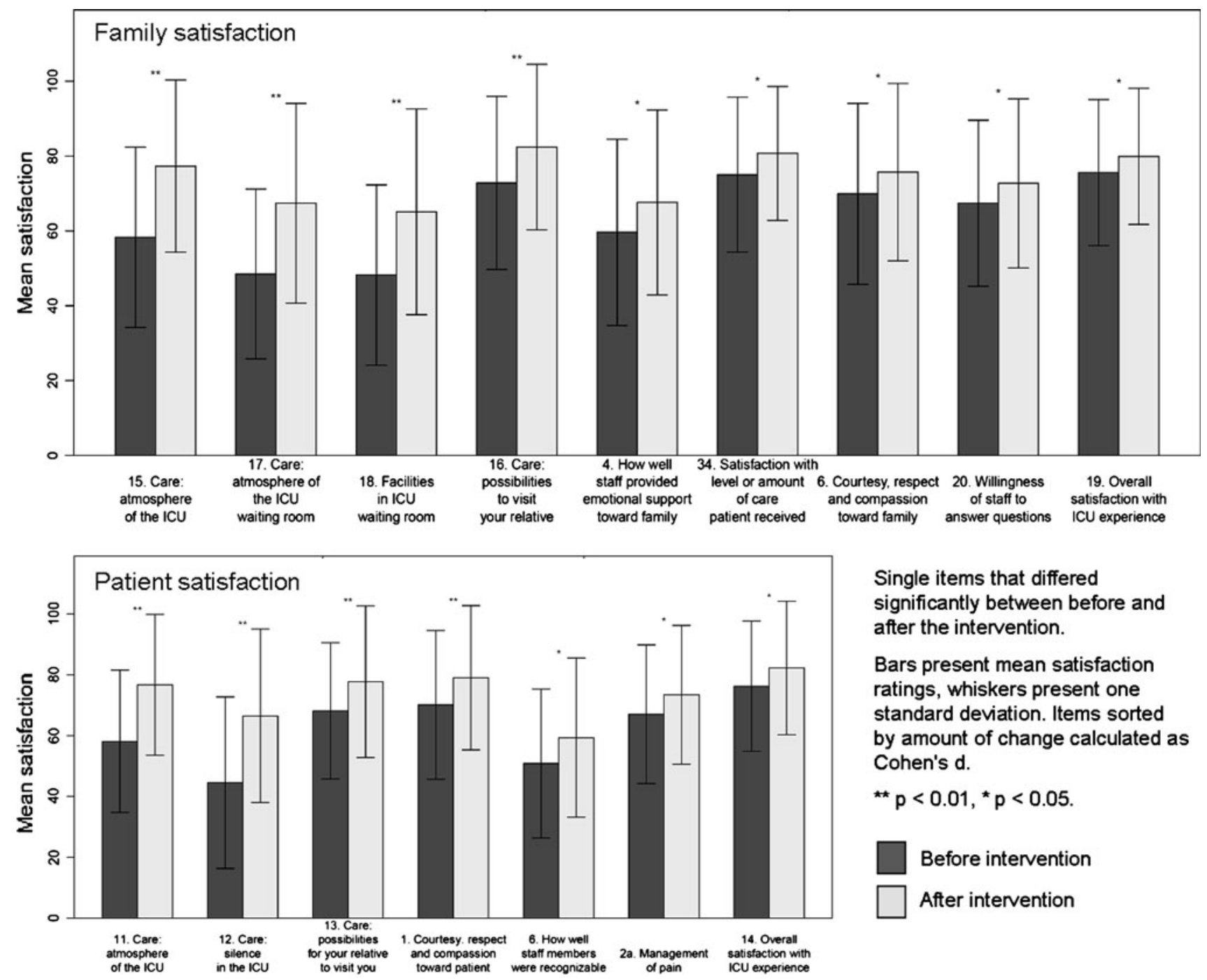

Single items that differed significantly between before and after the intervention.

Bars present mean satisfaction ratings, whiskers present one standard deviation. Items sorted by amount of change calculated as Cohen's d.

${ }^{\star} \mathrm{p}<0.01,{ }^{\star} \mathrm{p}<0.05$.

Before intervention

After intervention

Fig. 1 All items from the family and patient satisfaction questionnaires that changed significantly after moving to the new ICU (data from Suppl. Tables V and VI [1])

There are some drawbacks to the study-the singlecenter design, the non-randomized nature of the trial, the before-and after approach whereby effects due to secular or seasonal changes cannot be ruled out, and the bundle of changes, which makes it impossible to distinguish effective from non-effective elements. The existing literature on effective interventions is ambiguous: for instance, an early study suggested that patients who recovered from cholecystectomy in rooms with a view into natural foliage had shorter hospital stays and required less potent analgesics [10], but a recent study suggests that windows with a view may not be effective to improve patient outcomes [11]. The study by Jongerden et al. does not provide evidence for the effect of the individual elements. It was also not documented whether some of the intended changes actually took place, for instance, before-and-after measurements of light and noise levels, the number and lengths of visits, etc.

Being an ICU patient or a family member of an ICU patient can be a devastating experience and can lead to long-term morbidity after the ICU stay [12], posttraumatic stress disorder (PTSD), and depression [13-15]. Whatever can be done to improve the ICU experience for patients and their families is therefore of the utmost importance. Even though the study by Jongerden et al. has some limits, it provides an important advance in improving patient- and family-reported outcomes. It also suggests that creating patient- and family-friendly environments in the ICU can change ratings of many aspects of staff performance in a positive way. If we strive to improve the patient and family experience of ICU care, we should pay attention to structural components of ICU care. 
Acknowledgments The CSCC is supported by the Federal Ministry of Education and Research (BMBF), Germany, grant no. 01EO1002. C.S.H. is the recipient of a BMBF grant to study endof-life care in the ICU.
Conflicts of interest The authors declare that no conflict of interest exists.

\section{References}

1. Jongerden IP, Slooter AJ, Peelen LM, Wessels H, Ram CM, Kesecioglu J, Schneider MM, van Dijk D (2013)

Effect of intensive care environment on family and patient satisfaction: a before-after study. Intensive Care Med. doi:10.1007/s00134-013-2966-0

2. Rothen HU, Stricker KH, Heyland DK (2010) Family satisfaction with critical care: measurements and messages. Curr Opin Crit Care 16:623-631

3. Osborn TR, Curtis JR, Nielsen EL, Back AL, Shannon SE, Engelberg RA (2012) Identifying elements of ICU care that families report as important but unsatisfactory: decision-making, control, and ICU atmosphere. Chest 142:1185-1192

4. Schwarzkopf D, Behrend S, Skupin $\mathrm{H}$, Westermann I, Riedemann NC, Pfeifer R, Gunther A, Witte OW, Reinhart K, Hartog CS (2013) Family satisfaction in the intensive care unit: a quantitative and qualitative analysis. Intensive Care Med 39:1071-1079

5. Stricker KH, Kimberger O, Brunner L, Rothen HU (2011) Patient satisfaction with care in the intensive care unit: can we rely on proxies? Acta Anaesthesiol Scand 55:149-156
6. Fitzpatrick R (1991) Surveys of patients satisfaction: I-Important general considerations. BMJ 302:887-889

7. Rhodes A, Moreno RP, Azoulay E, Capuzzo M, Chiche JD, Eddleston J, Endacott R, Ferdinande P, Flaatten H, Guidet B, Kuhlen R, Leon-Gil C, Martin Delgado MC, Metnitz PG, Soares M, Sprung CL, Timsit JF, Valentin A (2012) Prospectively defined indicators to improve the safety and quality of care for critically ill patients: a report from the task force on safety and quality of the European society of intensive care medicine (ESICM). Intensive Care Med 38:598-605

8. Schleyer AM, Curtis JR (2013) Family satisfaction in the ICU: why should ICU clinicians care? Intensive Care Med 39:1143-1145

9. Flaatten H (2012) The present use of quality indicators in the intensive care unit. Acta Anaesthesiol Scand 56:1078-1083

10. Ulrich RS (1984) View through a window may influence recovery from surgery. Science 224:420-421

11. Kohn R, Harhay MO, Cooney E, Small DS, Halpern SD (2013) Do windows or natural views affect outcomes or costs among patients in ICUs? Crit Care Med. doi:10.1097/CCM.0b013e31828 $7 \mathrm{f} 6 \mathrm{cb}$
12. Wolters AE, Slooter AJ, van der Kooi AW, van Dijk D (2013) Cognitive impairment after intensive care unit admission: a systematic review. Intensive Care Med 39:376-386

13. Azoulay E, Pochard F, Kentish-Barnes N, Chevret S, Aboab J, Adrie C, Annane D, Bleichner G, Bollaert PE, Darmon M, Fassier T, Galliot R, Garrouste-Orgeas M, Goulenok C, Goldgran-Toledano D, Hayon J, Jourdain M, Kaidomar M, Laplace C, Larche J, Liotier J, Papazian L, Poisson C, Reignier J, Saidi F, Schlemmer B (2005) Risk of post-traumatic stress symptoms in family members of intensive care unit patients. Am J Respir Crit Care Med 171:987-994

14. Gries CJ, Engelberg RA, Kross EK, Zatzick D, Nielsen EL, Downey L, Curtis JR (2010) Predictors of symptoms of posttraumatic stress and depression in family members after patient death in the ICU. Chest 137:280-287

15. Davidson JE, Jones C, Bienvenu OJ (2012) Family response to critical illness: postintensive care syndromefamily. Crit Care Med 40:618-624 